\section{Lesões cutâneas em uma doente com mieloma múltiplo em remissão hematológica}

\section{Cutaneous lesions in a patient with multiple myeloma in hematological remission}

0 mieloma múltiplo (MM) carateriza-se pela proliferação neoplásica de um clone de plasmócitos, frequentemente produtores de imunoglobulina monoclonal ${ }^{1}$. 0 atingimento cutâneo associado ao MM ocorre em 5 a $10 \%$ dos casos². Os plasmocitomas secundários são considerados manifestações cutâneas específicas de MM, que podem ocorrer por extensão direta para a pele, a partir de lesões ósseas subjacentes, ou por disseminação hematógena ${ }^{2,3}$. Os autores apresentam o caso de uma doente de 75 anos, com o diagnóstico de MM IgG lambda, submetida a quimioterapia sistémica com bortezomib, ciclofosfamida e dexametasona, com boa resposta. Manteve-se sob terapêutica de manutenção com talidomida, sem sinais de recorrência hematológica. Três anos após o diagnóstico surgiram pápulas e nódulos eritematosos com localização no terço superior do tronco, braços e raiz do pescoço (Figuras 1 e 2). Sem alterações valorizáveis ao exame objetivo ou nos parâmetros analíticos. A biópsia cutânea incisional mostrou uma lesão nodular na derme formada por agregados densos de células com nítida transformação plasmocitária, compatível com o diagnóstico de plasmocitoma cutâneo. 0 tratamento geralmente inclui a combinação de quimioterapia, radioterapia local e/ou excisão cirúrgica ${ }^{3}$. Contudo, verificou-se uma rápida deterioração do estado geral, tendo-se optado por não efetuar nenhum outro ciclo de terapêutica sistémica. Neste momento a doente encontra-se em cuidados paliativos. Salientamos a importância do reconhecimento dos plasmocitomas consequentes a disseminação do MM, pois são reflexo da elevada carga tumoral, ocorrendo geralmente em fases tardias da doença ${ }^{2,3}$. 0 nosso caso ilustra o mau prognóstico associado à metastização cutânea, com 50\% dos pacientes evoluindo para o óbito em seis meses, apesar das alternativas terapêuticas ${ }^{3,4}$.

\section{Bibliografia}

1. Kyle R. e Rajkumar V., Multiple Myeloma, Blood. 2008 Mar 15 111(6): 2962-72

2. Requena L, Kutzner H., Palmedo G., Calonje E., Requena C., et al, Cutaneous Involvement in multiple mieloma, Arch Dermatology 2003; 139:475-86.

3. Araújo C., Marques H., Fernandes J.C., Pardal A., Brito C., Cutaneous Plasmacytomas Secondary to Nonsecretory Multiple Myeloma, J Dermatolog Clin Res 2014; 2(3): 1022

4. Souza D, Freitas T., Paes R., Müller H., Hungria V., Mieloma Múltiplo com Plasmocitomas Cutâneos, An Bras Dermatol, 2004; 79(5):581-5.

\section{Diagnóstico: Plasmocitoma cutáneo metastásico em doente com mieloma múltiplo}

A.S. Montez, E. Rocha

Serviço de Medicina Interna. Centro Hospitalar do Baixo Vouga. Aveiro. Portugal
Figura 1. Lesões de plasmocitoma cutâneo.

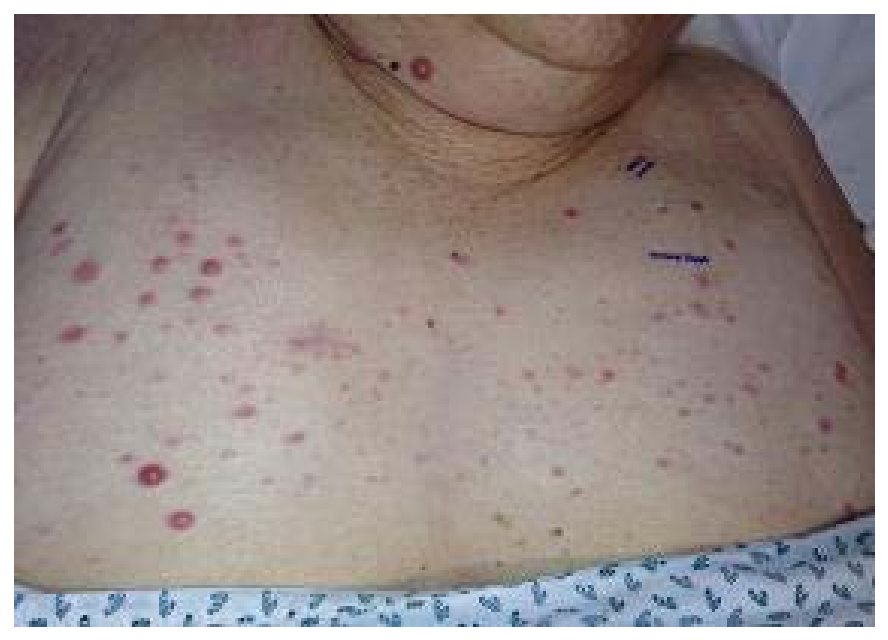

Figura 2. Plano mais aproximado das lesões de plasmocitoma cutâneo. 